\title{
Ampulla of Vater Invasive Papillary Adenocarcinoma
}

National Cancer Institute

\section{Source}

National Cancer Institute. Ampulla of Vater Invasive Papillary Adenocarcinoma. NCI

Thesaurus. Code 695967.

An invasive adenocarcinoma that arises from an exophytic papillary neoplasm of the ampulla of Vater. 